\title{
Thoracic epidural analgesia to control malignant pain until viability in a pregnant patient
}

\author{
This article was published in the following Dove Press journal: \\ Journal of Pain Research \\ 13 June 2016 \\ Number of times this article has been viewed
}

\author{
Jaideep H Mehta' \\ Mary Elizabeth Gibson ${ }^{2}$ \\ David Amaro-Driedger ${ }^{3}$ \\ Mahammad $\mathrm{N}$ Hussain' \\ 'Department of Anesthesiology, UT \\ Health, McGovern Medical School, \\ Houston, TX, ${ }^{2}$ Orlando Health, \\ Orlando, FL, ${ }^{3}$ UT Health, McGovern \\ Medical School, Houston, TX, USA
}

\begin{abstract}
Management of nonobstetric pain in the pregnant patient presents unique challenges related to transplacental fetal exposure to opioids and the subsequent risk of neonatal withdrawal syndrome. We present the case of a pregnant patient suffering from the pain of a progressively enlarging thoracoabdominal sarcoma. Epidural analgesia (using local anesthetics with minimal opioid) was utilized over a span of weeks to manage oncologic pain, limiting fetal opioid exposure and culminating in the birth of a healthy infant. While nonobstetric abdominal pain during pregnancy is not that uncommon, neoplastic abdominal pain does appear to be rare. Combined local anesthetic and opioid continuous epidural infusion should be considered a viable option in the pain management approach to obstetric patients with nonobstetric pain associated with malignancy.
\end{abstract}

Keywords: epidural, pregnancy, malignant, sarcoma

\section{Introduction}

Nonobstetric pain management in the gravid patient presents the challenge of safely and effectively managing two patients simultaneously and requires consideration of potential risk and benefit to mother, fetus, and the course of pregnancy. ${ }^{1-3}$ Traditional pain management approaches, specifically the use of high-dose opioids, place the fetus at risk for withdrawal symptoms after delivery. ${ }^{4}$ We describe a case of a pregnant woman with malignancy-related pain treated for 3 weeks with an epidural infusion of low-dose ropivacaine and fentanyl. The Committee for the Protection of Human Subjects approved the retrospective review of this case, and written consent from the patient for the publication of this case report was obtained, prior to her passing.

\section{Case description}

A 32-year-old G2P1 female presented to the acute pain medicine (APM) service with a history of uncontrolled thoracoabdominal pain secondary to an aggressively growing sarcoma. Pain was first reported at 10 weeks of pregnancy. Imaging studies at that time revealed a $5.8 \mathrm{~cm}$ craniocaudal $\times 3.6 \mathrm{~cm}$ transverse $\times 3.7 \mathrm{~cm}$ lobulated retroperitoneal mass. At 22 weeks, the patient underwent laparoscopic excision of a left-sided retroperitoneal mass. The patient was discharged home with a diagnosis of a benign tumor, and her pain was controlled with one hydrocodone/acetaminophen $10 \mathrm{mg} / 325 \mathrm{mg}$ tablet every 4-6 hours. In addition, the obstetrician prescribed highdose oral steroids, in an attempt to halt the growth of the mass.
Correspondence: Jaideep H Mehta Department of Anesthesiology, U 643 I Fannin Street, MSB 5.020, Houston, TX 77030, USA

Tel + I 7135006200

Fax + I 7|3500620|

Email Jaideep.H.Mehta@gmail.com (c) (i) (5) 2016 Mehta et al. This work is published and licensed by Dove Medical Press Limited. The full terms of this license are available at https://www.dovepress.com/terms. cc) ${ }_{\mathrm{BY}} \mathrm{NC}$ php and incorporate the Creative Commons Attribution - Non Commercial (unported, v3.0) License (http://creativecommons.org/licenses/lby-nd/3.0/). By accessing the work you hereby accept the Terms. Non-commercial uses of the work are permitted without any further permission from Dove Medical Press Limited, provided the work is properly attributed. For

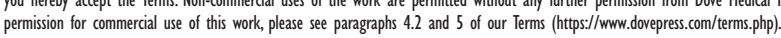


She was readmitted to the hospital at 26 weeks 3 days of pregnancy complaining of worsening, unrelenting pain. Magnetic resonance imaging from the Emergency Department indicated a suboptimal resection of a retroperitoneal mass. The patient's pain was controlled overnight by the APM service with 5-10 mg oxycodone as needed every 4 hours for breakthrough pain. She was discharged home the following day with prescriptions for oxycodone extended release $10 \mathrm{mg}$ every 8 hours and one to two tablets of hydrocodone/acetaminophen $10 \mathrm{mg} / 325 \mathrm{mg}$ every 4 hours for breakthrough pain. However, she returned to the Emergency Department 3 days later with uncontrolled pain, at which point an abdomen/pelvis computed tomography with contrast revealed an increase in the size of the soft tissue mass in the left retroperitoneum, extending posteriorly to the kidney and superiorly to the spleen. Multiple separate lesions were also invading the spleen, left hemidiaphragm, peritoneum, bilateral pulmonary parenchyma, and left ventricle. The patient was discharged home with a prescription for a fentanyl $12.5 \mathrm{mg} / \mathrm{hr}$ patch in addition to her prior oral regimen.

The patient returned again 2 days later and was admitted with 10/10 pain. During this admission, the patient recognized the lack of relief from her increasingly large narcotic regimen and expressed a desire to avoid opioids to improve fetal outcome. The obstetrics and neonatal services stated their desire to continue the pregnancy until a planned delivery at 30 weeks in order to improve the outcome for the fetus. The APM team determined that neuraxial analgesia was a viable option, with potential for more targeted segmental pain control and minimal fetal risk.

A thoracic epidural catheter was inserted via the T8/9 space, and a bolus of $10 \mathrm{~mL}$ of $0.1 \%$ ropivacaine with $2 \mu \mathrm{g} / \mathrm{mL}$ fentanyl was administered, resulting in a sensory block from T4 to L2. An occlusive transparent sterile dressing with chlorhexidine-impregnated gel was placed over the site to maintain sterility. The patient reported significant pain relief, with her pain score dropping from $8 / 10$ to $2 / 10$. A patient-controlled epidural analgesia of $0.1 \%$ ropivacaine with $2 \mu \mathrm{g} / \mathrm{mL}$ fentanyl epidural infusion was started at $10 \mathrm{~mL} / \mathrm{hr}$, with patient-controlled bolus option of $5 \mathrm{~mL}$ every 20 minutes with a maximum of $20 \mathrm{~mL} / \mathrm{hr}$. The pain relief provided by this epidural allowed the patient to rest comfortably, tolerate oral intake, and ambulate. Over the subsequent 2 weeks, the epidural catheter was replaced twice as per the APM service protocol, on Day 5 and Day 12, in an attempt to continue to cover breakthrough pain in the left abdomen and chest wall, as well as reduce the likelihood of epidural site infection.
Despite excellent pain control, aggressive nutrition, hydration, and electrolyte management, the patient became increasingly tachypneic, lethargic, and cachectic over the following 2 weeks. The obstetrics service induced labor at 29 weeks 2 days of pregnancy in response to an overall decline in the patient's clinical picture. A combined spinal epidural anesthetic, with $1 \mathrm{~mL}$ of $0.25 \%$ bupivacaine in the spine and a $0.1 \%$ ropivacaine with $2 \mu \mathrm{g} / \mathrm{mL}$ of fentanyl infusion at $8 \mathrm{~mL} / \mathrm{hr}$ in the epidural space at L3/4, was used to control pain in the final stages of labor. The thoracic epidural was maintained in place at $\mathrm{T} 8 / 9$ and continued in order to manage the cancer pain during labor. The patient had an uncomplicated vaginal delivery of a 1,410 g infant, with Apgar scores of 6.0 and 8.0, without complication or signs of neonatal withdrawal, as the patient had received minimal opioids for $\sim 3$ weeks. Both epidural catheters were removed shortly after delivery without complications. On postpartum day 1, the patient was started on a multimodal pain management regimen, consisting of acetaminophen, ibuprofen, methadone for long-acting pain control, and oxycodone for breakthrough pain. ${ }^{5}$ She was subsequently discharged that afternoon to a quaternary oncology facility for the initiation of chemotherapy for her cancer, which was ultimately clinically diagnosed as a rare rhabdomyosarcoma by the oncologist without additional biopsies. No additional information was available to the team regarding additional workup for congenital rhabdomyosarcoma in either of the surviving children, nor was there information on follow-up after prolonged high-dose administration of opioids early in pregnancy. Although the patient underwent aggressive chemotherapy, she ultimately succumbed to the cancer.

\section{Discussion}

This case deals with the difficult question of how to appropriately manage severe, progressive, oncologic pain in a patient with a viable pregnancy. Rathmell et al $^{3}$ focused on fetal risks associated with in utero exposure to specific drug classes and discussed management of headache, back pain, and sickle cell crisis, as examples of chronic pain in the obstetric patient. Fetal risks can include dependence on narcotics used to alleviate the mother's pain; in this case, the male baby showed no signs of opioid withdrawal after delivery.

Our case is unique because our patient's pain was a direct result of an aggressively growing metastatic malignancy, which was initially misdiagnosed as a benign tumor. It is likely that pregnancy-associated hormones may have contributed to the aggressive nature of the tumor, while the 
physical changes of pregnancy, as implicated in the case reported by Samlaska and Dews, ${ }^{6-8}$ were not the causes of pain in this case. Their case involved long-term epidural analgesia for an intercostal neuralgia. Moreover, in the case described by Samlaska and Dews, ${ }^{8}$ the patient was discharged home, epidural in place, with home nursing care for dressing changes and infusion pump management, and the epidural was discontinued at the onset of spontaneous labor per the patient's desire for natural childbirth. Considering the volatile nature of our patient's condition and the dynamic nature of the pain of oncologic origin, treating the patient at home using epidural analgesia was not a prudent or feasible option. Palliative chemotherapy could have also been considered, but it was not used due to the risks to the viable fetus and the lack of pathology confirming malignancy. ${ }^{9}$ While genetics and heritability of the condition may have played a role in the development of the tumor, no cytogenetic analysis was performed during either the pregnancy or delivery hospitalization.

In this case, many pharmaceutical options were eliminated because of concern regarding transplacental transfer to the fetus. Fetal exposure to nonsteroidal anti-inflammatory drugs (NSAIDs) may cause premature constriction of the ductus arteriosus, which may result in fetal pulmonary hypertension. ${ }^{10-12}$ Other reported effects of in utero exposure to NSAIDs include intracranial hemorrhage, necrotizing enterocolitis, oligohydramnios, and renal dysfunction; additionally, there is increased risk of peripartum and postpartum hemorrhage..$^{13}$

Increased incidences of fetal structural abnormalities and other manifestations of developmental toxicity, including lethality, growth restriction, and nervous and reproductive system functional impairment were demonstrated in studies of pregabalin in rats. ${ }^{14}$ Decreased fetal weights, skeletal ossification, and developmental delays were demonstrated in animal studies of tramadol; neonatal seizures, neonatal withdrawal syndrome, fetal death, and stillbirth have all been reported during postmarketing surveillance. ${ }^{15}$ Opioids, including morphine, hydromorphone, methadone, oxycodone, and hydrocodone, do cross the placenta and may cause respiratory depression and life-threatening neonatal withdrawal syndrome. ${ }^{3,16,17}$ A newborn infant in opioid withdrawal is usually small for gestational age, often shows signs of intrauterine growth retardation, and demonstrates the following: yawning, sneezing, decreased Moro reflex, hunger with an uncoordinated sucking action, jitteriness, tremor, constant movement, a shrill protracted cry, increased tendon reflexes, convulsions, vomiting, fever, watery diarrhea, cyanosis, dehydration, vasomotor instability, seizure, and cardiovascular collapse. ${ }^{18,19}$ No specific treatment protocol has been shown to be effective for neonatal withdrawal syndrome, and these infants often have chronic neurobehavioral handicaps. ${ }^{19}$ As previously mentioned, there was no evidence that this baby underwent opioid withdrawal after delivery.

We elected to use a $0.1 \%$ ropivacaine with $2 \mu \mathrm{g} / \mathrm{mL}$ fentanyl epidural infusion for management of the severe pain, in an effort to reduce the risk of neonatal withdrawal syndrome and postdelivery apnea in the preterm infant. Spinal or epidural opioids, especially when combined with dilute solutions of local anesthetics, can provide excellent analgesia for thoracic, abdominal, or pelvic pain without the side effects associated with large doses of systemically administered opioids. ${ }^{20}$ As fentanyl is a lipophilic opioid, it is frequently preferred for its ability to provide segmental analgesia as opposed to hydrophilic morphine, which has a more rostral spread. The APM team elected to use a dilute ropivacaine with low-dose fentanyl epidural infusion under the premise that the addition of fentanyl would offer better pain control than plain ropivacaine for the dynamic, spasmodic episodes of thoracoabdominal pain, by inhibiting pain transmission at the dorsal horn of the spinal cord., ${ }^{4,21}$ The major advantages of using a combination of opioid and local anesthetic in epidural infusion are the rapid onset of pain relief, a decrease in shivering, and less dense motor blockade. ${ }^{22}$

We demonstrate that high thoracic epidural analgesia, in lieu of systemic opioids, provided adequate pain control for the patient with severe thoracoabdominal pain, with resultant healthy neonatal outcome. Combined local anesthetic and opioid continuous epidural infusion can be a safe and viable option in the pain management approach to obstetric patients with nonobstetric pain.

\section{Acknowledgment}

This study did not receive any external funding.

\section{Author contributions}

All authors contributed toward data analysis, drafting and critically revising the paper and agree to be accountable for all aspects of the work.

\section{Disclosure}

The authors report no conflicts of interest in this work.

\section{References}

1. Epstein FB. Acute abdominal pain in pregnancy. Emerg Med Clin North Am. 1994;12(1):151-165. 
2. Spalluto LB, Woodfield CA, DeBenedectis CM, Lazarus E. MR imaging evaluation of abdominal pain during pregnancy: appendicitis and other nonobstetric causes. Radiographics. 2012;32(2):317-334.

3. Rathmell JP, Viscomi CM, Ashburn MA. Management of nonobstetric pain during pregnancy and lactation. Anesth Analg. 1997;85:1074-1087.

4. Schumacher MA, Basbaum AI, Way WL. Chapter 31. Opioid analgesics and antagonists. In: Katzung BG, Masters SB, Trevor AJ, editors. Basic and Clinical Pharmacology. 12th ed. New York: McGraw-Hill; 2012.

5. American Society of Anesthesiologists Task Force on Chronic Pain Management; American Society of Regional Anesthesia and Pain Medicine. Practice guidelines for chronic pain management: an updated report by the American Society of Anesthesiologists Task Force on Chronic Pain Management and the American Society of Regional Anesthesia and Pain Medicine. Anesthesiology. 2010;112(4):810-833.

6. Yazigi R, Driscoll SG. Sarcoma complicating pregnancy. Gynecol Oncol. 1986;25(1):125-127.

7. Jafari K, Lash AF, Webster A. Pregnancy and Sarcoma. Acta Obstet Gynecol Scand. 1978;57(3):265-271.

8. Samlaska S, Dews TE. Long-term epidural for pregnancy-induced intercostal neuralgia. Pain. 1995;62(2):245-248.

9. Taghavi K, Sykes P, Innes C, et al. Wrong place at the wrong time: a case of cervical embryonal rhabdomyosarcoma in pregnancy. Gynecol Oncol Rep. 2015;12:77-79.

10. Prefumo F, Marasini M, De Biasio P, Venturini PL. Acute premature constriction of the ductus arteriosus after maternal self-medication with nimesulide. Fetal Diagn Ther. 2008;24:35-38.

11. Lubetzky R, Mandel D, Mimouni FB, et al. Indomethacin-induced early patent ductus arteriosus closure cannot be predicted by a decrease in pulse pressure. Am J Perinatol. 2004;21:257-261.

12. Gewillig M, Brown SC, De Catte L, et al. Premature foetal closure of the arterial duct: clinical presentations and outcome. Eur Heart J. 2009;30(12):1530-1536.

13. Rella JG, Carter WA. Chapter 185. Nonsteroidal Anti-Inflammatory Drugs. In: Tintinalli JE, Stapczynski JS, Cline DM, Ma OJ, Cydulka RK, Meckler GD, editors. Tintinalli's Emergency Medicine: A Comprehensive Study Guide. 7th ed. New York: McGraw-Hill; 2011.
14. Lyrica (full prescribing information) [webpage on the Internet]. New York, NY: Pfizer Pharmaceuticals, LLC., Division of Pfizer, Inc.; 2012. Available from: http://labeling.pfizer.com/ShowLabeling.aspx?id=561. Accessed January 26, 2013.

15. Ultram (full prescribing information) [webpage on the Internet]. Raritan, NJ: PriCara, Division of Ortho-McNeil-Janssen Pharmaceuticals, Inc.; 2009. Available from: http://www.janssenpharmaceuticalsinc.com/ assets/ultram.pdf. Accessed January 26, 2013.

16. OxyContin (full prescribing information) [webpage on the Internet]. Stamford, CT: Purdue Pharma, L.P.; 2011. Available from: http://www. purduepharma.com/pi/prescription/OxycontinPI.pdf. Accessed January 26, 2013.

17. Vicodin (full prescribing information) [webpage on the Internet]. North Chicago, IL: Abbott Laboratories; 2012. Available from: http://www. rxabbvie.com/pdf/vicodin_apap_300mg_hydrocodone_5mg-7.5mg10mg_PI.pdf. Accessed January 26, 2013.

18. Rumack BH, Dart RC. Chapter 13. Poisoning. In: Hay WW Jr, Levin MJ, Deterding RR, Ross JJ, Sondheimer JM, editors. CURRENT Diagnosis and Treatment: Pediatrics. 21st ed. New York: McGraw-Hill; 2012.

19. Thilo EH, Rosenberg AA. Chapter 2. The Newborn infant. In: Hay WW Jr, Levin MJ, Deterding RR, Ross JJ, Sondheimer JM, editors. CURRENT Diagnosis and Treatment: Pediatrics. 21st ed. New York: McGraw-Hill; 2012.

20. Catterall WA, Mackie K. Chapter 20. Local anesthetics. In: Brunton LL, Chabner BA, Knollmann BC, editors. Goodman and Gilman's the Pharmacological Basis of Therapeutics. 12th ed. New York: McGrawHill; 2011.

21. Adams MC, Tighe PJ, Hurley RW. Chapter 96. Pain. In: Lawry GV, McKean SC, Matloff J, Ross JJ, Dressler DD, Brotman DJ, Ginsberg JS, editors. Principles and Practice of Hospital Medicine. New York: McGraw-Hill; 2012.

22. Cunningham FG, Leveno KJ, Bloom SL, Hauth JC, Rouse DJ, Spong CY. Chapter 19. Obstetrical Anesthesia. In: Cunningham FG, Leveno KJ, Bloom SL, Hauth JC, Rouse DJ, Spong CY, editors. Williams Obstetrics. 23rd ed. New York: McGraw-Hill; 2010.
Journal of Pain Research

\section{Publish your work in this journal}

The Journal of Pain Research is an international, peer-reviewed, open access, online journal that welcomes laboratory and clinical findings in the fields of pain research and the prevention and management of pain. Original research, reviews, symposium reports, hypothesis formation and commentaries are all considered for publication.

\section{Dovepress}

The manuscript management system is completely online and includes a very quick and fair peer-review system, which is all easy to use. Visit http://www.dovepress.com/testimonials.php to read real quotes from published authors. 